\title{
Generation of Electrical Energy Obtained Through a Continuous Current Generator Coupled to the Pedal of an Ergometric Bicycle
}

\author{
Lilian Vaselquiu Muller ${ }^{1 *}$, Paulo Cícero Fritzen ${ }^{\mathbf{1}}$, Ednilson Soares Maciel ${ }^{2}$
}

${ }^{1}$ Programa de Pós-Graduação em Sistemas de Energia, Universidade Tecnológica Federal do Paraná, Curitiba, Brasil; ${ }^{2}$ Departamento Acadêmico de Eletrotécnica, Universidade Tecnológica Federal do Paraná, Curitiba, Paraná, Brasil.

\begin{abstract}
This study presents a system of conversion of mechanical energy produced by physical activity into electric energy obtained by a CC generator coupled to the pedal of an ergometric bicycle. It presents the converter that will be used to adjust the voltage and power coming from the system, as well as the details of the converter design, the simulation and the primary experimental results of the structure. The methodological procedures related to the development of the converter and data acquisition through simulation were carried out based on the bibliographic research. The study is documentary as equipment manuals were used.
\end{abstract}

Keywords: renewable energy generation sources, power generation, CC converter, human effort, direct current machine.

\footnotetext{
* Author of correspondence: lilian.muller@pr.senai.br
} 


\section{INTRODUCTION}

The increase in energy demands aligned with the decline in natural resources have resulted in a demand for the development of renewable energy sources. Human-generated energy is a form of renewable energy that has been used. Large amount of energy from human effort is produced every day as sports and recreational activities.

The recovery of energy wasted during these recreational activities has been proposed and applied on a small scale [5].

In this context, gyms, sports centers consume electricity not only to power equipment such as treadmills, bicycles, ellipticals, but also to satisfy the comfort of their customers, such as sound equipment or televisions, adequate lighting and air conditioning systems [1]. The energy people spend doing exercises in the gym is lost in the form of heat, and this lost energy could be converted into a useful form of energy.

Some studies show that there are several sustainable gyms around the planet, many of them installed within universities [1].

In order to become sustainable, these gyms make improvements and study energy efficiency in the lighting system in order to reduce the energy consumption for lighting, they also assess the consumption of each equipment for practice of exercises and how much each of them can generate electrical energy, using human effort.

The installation of generators and batteries in treadmills, bicycle pedals and elliptical machines have been some of the solutions for producing and storing electricity [1]. Studies done at the University of Oxford has shown that a cyclist could easily produce on average $75 \mathrm{~W}$ of sustainable electric power with a voltage of $12 \mathrm{~V}$ and a speed of 900 revolutions per minute for a period of one hour [5]. In this context, in order to adjust the voltage produced by the generator, one of the minimum infrastructures for microgeneration is the use of converting equipment, based on the power electronics, to connect and control the various sources of generation and energy storage, as well as special loads [2] [5].

The present work deals with a study for the generation of electric energy, from the conversion of the mechanical energy of the physical activity of pedaling. A $\mathrm{CC}$ machine was adapted as a generator to the axis of the bicycle. The generation system proposed in this work produces voltage below the voltage that must be delivered for power supply, and for this reason, a technique will be used to associate a not isolated CC converter in the system (the converter Boost with multiplying cell) in continuous conduction for voltage increase. This converter topology for voltage adequacy is proposed by [1].and the energy produced is connected to a $\mathrm{CC}$ bar.

The objective of this work is to develop a system for generation and control of electric energy obtained through human effort applied to an ergometer bicycle pedal coupled to a direct current generator. 


\section{MATERIAL AND METHODS}

This study is characterized as an applied field research because the field research is carried out in the field or habitat and free of alterations made by the researcher, having as a start the observation of events and these events must be recorded as they happen [4], with real data collection because it makes "specification of the objectives, operationalization of concepts and variables, elaboration of the instrument of data collection, instrument testing, data collection and verification, analysis and interpretation" [8].

It is documentary, since it uses data provided by manufacturers, such as: the descriptive system memo, the controller electrical diagrams and electronic components datasheets [6].

The first step was the bibliographical research that will provide the state of the art on the necessary concepts for the development of this study.

The second stage is composed of a study on energy conversion that is divided into the following stages.

a) Mechanical structure.

This article uses a system that converts mechanical to electrical energy. Table 1 shows the nominal values of the $\mathrm{CC}$ machine.

Table 1 - Nominal values of the CC machine.

\begin{tabular}{llll}
\hline $\begin{array}{l}\text { Power } \\
(\mathrm{W})\end{array}$ & $\begin{array}{l}\text { Voltage } \\
(\mathrm{V})\end{array}$ & $\begin{array}{l}\text { Current } \\
(\mathrm{A})\end{array}$ & $\begin{array}{l}\text { Rotation per } \\
\text { minute } \\
(\mathrm{rpm})\end{array}$ \\
\hline 120 & 30 & 4,3 & 600 \\
\hline
\end{tabular}

Figure 1 shows the prototype that was developed in this article. A device which allows the pedal of the stationary bicycle to be connected to the generator shaft has been adapted.

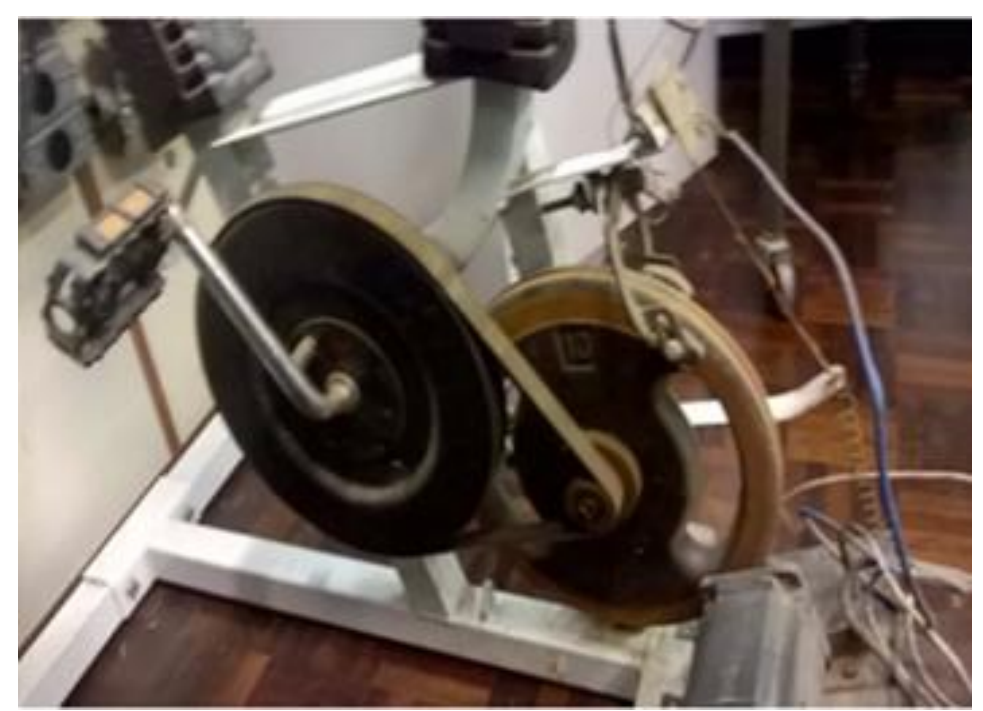

Figure1 - Bicycle ergometer prototype.

Source: Authors

A person with a good physical training when riding is able to achieve approximately 300 rotations per minute on average [2]. 
The CC machine used has a directly proportional relationship between the rotation exerted on its axis and the voltage produced at its output terminals [2]. The power extracted from the direct current (CC) generator is equivalent to the effort applied to the pedal at the time of physical exercise, ie, the higher the level of power requested by the system, the greater the physical effort required to supply it [2].

According to the characteristics of the generator, a high voltage converter is required. The next topic will deal with the converter topology adopted for use in this study.

b) CC-CC converter design

This stage will briefly address the operation, the main equations governing the behavior of the CC-CC voltage converter circuit, since they are essential for circuit design.

The topology of the high gain boost CC-CC converter [7] is shown in Figure 2.

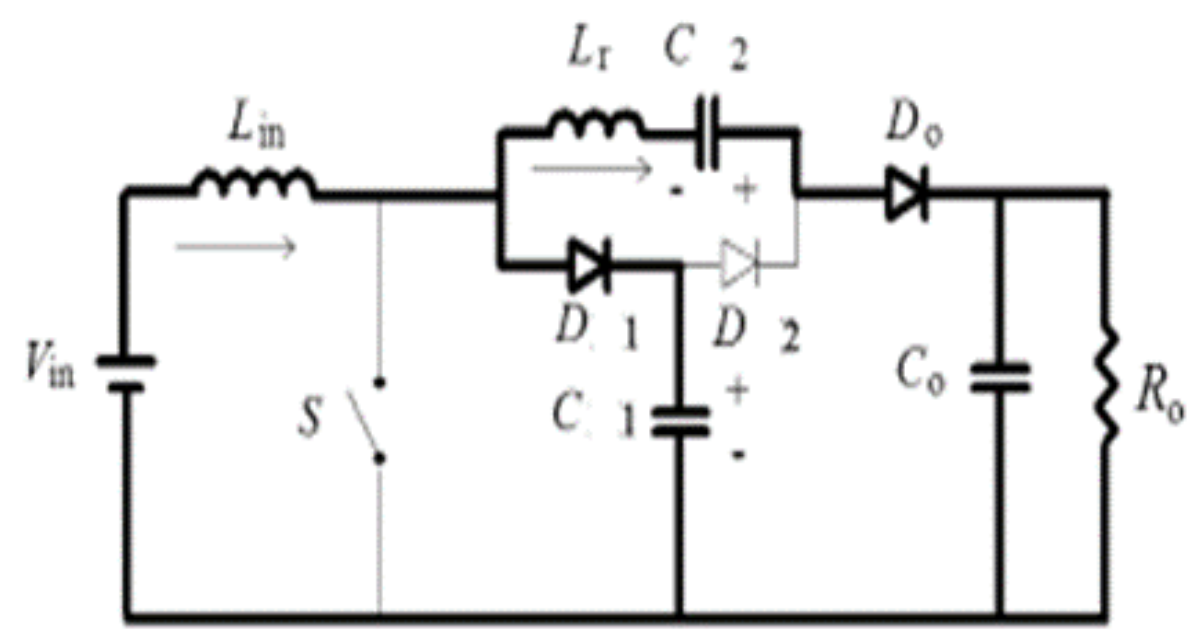

Figure 2 - CC-CC Boost converter in first stage of operation.

Source: Prudente, Pfitscher, Emmendoerfer, Romaneli, Gules UTFPR (2008).

The converter shown in figure 2 is responsible for raising the voltage of the generator whose voltage is $30 \mathrm{~V}$ to the voltage of the power transmission to the load. Table 2 summarizes the project specifications.

Table 2 - Project Specifications

\begin{tabular}{|c|c|c|c|}
\hline Input Voltage $\mathrm{Vi}$ & Output Voltage Vo & Current I & Power \\
\hline $30 \mathrm{~V}$ & $250 \mathrm{~V}$ & $4 \mathrm{~A}$ & $120 \mathrm{~W}$ \\
\hline
\end{tabular}

Source: Authors 
The transmission voltage is $250 \mathrm{~V}$; therefore, a gain of $8.33 \mathrm{~V}$ is required. At first, the use of a simple $\mathrm{CC}$ boost converter could be considered, but to achieve the required voltage gain, the duty cycle would need to operate at 0.879 . This value is too close to the operating limit of 0.9 , which makes the use of this topology unfeasible.

Equation (1) expresses the gain ratio for operation in continuous conduction mode ${ }^{7}(\mathrm{CCM})$.

$\frac{\text { Vout }}{\text { Vin }}=\mathrm{D}$

Where:

Vout: Output voltage.

Vin: Input voltage.

D: cyclic converter ratio.

Equation (2) shows the load value seen by the circuit.

$$
P o=\frac{\text { Vout }^{2}}{\operatorname{Vin}}
$$

Where:

Po: Output power.

Vout: Output voltage.

R: Resistance.

The average current in the inductor is determined by equation (3).

$I L=\frac{(V o * I o)}{\operatorname{Vin}}$

Where:

IL: Inductor Current.

Io: Output current.

The designed converter will operate in continuous conduction mode and will have the Lin inductor with value as shown in equation 6 . The input inductance is the same as the traditional boost converter. The inductor curl current was adopted equal to $35 \%$ of the nominal input inductance current, then the input inductance value and the equations for the input inductance will be presented. The effective current in the inductor is approximately equal to the average input current.

$$
\begin{aligned}
\Delta \mathrm{iL} & =\frac{\text { Po }}{\mathrm{Vin}} * 0,35 \\
L \mathrm{in} & =\frac{\mathrm{Vin} * \mathrm{D}}{\Delta \mathrm{iL} * \mathrm{f}}
\end{aligned}
$$


Where:

$\Delta \mathrm{iL}$ : Average current in the inductor.

f: Frequency of the converter.

Lin: Inductor.

The multiplier capacitor C2 is charged with the output voltage of the classic boost converter, as this capacitor is connected in series with the output of the converter in the transfer of the energy stored by the input inductance Lin, the output capacitor is charged with the output voltage multiplied by two as shown in equations 6 and 7.

$\mathrm{VC} 1=\mathrm{VC} 2=\frac{\mathrm{Vi}}{(1-\mathrm{D})}$

$\mathrm{VCo}=\mathrm{VC} 2+\frac{\mathrm{Vi}}{(1-\mathrm{D})}$

VC1: Voltage in capacitor 1

VC2: Voltage in capacitor 2

VCo: Output voltage on output capacitor.

The voltage at the switch and the diodes will be equal to half the output voltage.

$\mathrm{VC} 1=\mathrm{Vs}=\mathrm{VD} 1=\mathrm{VD} 2=\frac{\mathrm{VCo}}{2}$

The capacitances in the capacitors $\mathrm{C} 1, \mathrm{C} 2$ and $\mathrm{C} 0$ are presented in equations 9 and 10 . A voltage ripple of $1 \%$ was adopted.

$C o=\frac{D}{R *\left(\frac{\Delta V 0}{V 0}\right) * f}$

$\mathrm{C} 1=\mathrm{C} 2=\mathrm{Io} * \frac{(1-\mathrm{D})}{\Delta \mathrm{Vo} * \mathrm{f}}$

Where:

Vo: Output voltage.

$\Delta$ Vo: Output voltage ripple.

The currents in the diodes and the average current in the key are calculated by equations 11 and 12 .

$\mathrm{ID} 1=\mathrm{ID} 2=\mathrm{IDO}=\frac{\mathrm{Po}}{\mathrm{Vo}}$

ISrms $=\frac{\text { Pin }}{\text { Vin }} * \sqrt{\mathrm{D}}$ 


\section{RESULT AND DISCUSSION}

Figure 3 shows the input current, and the current in the switch.

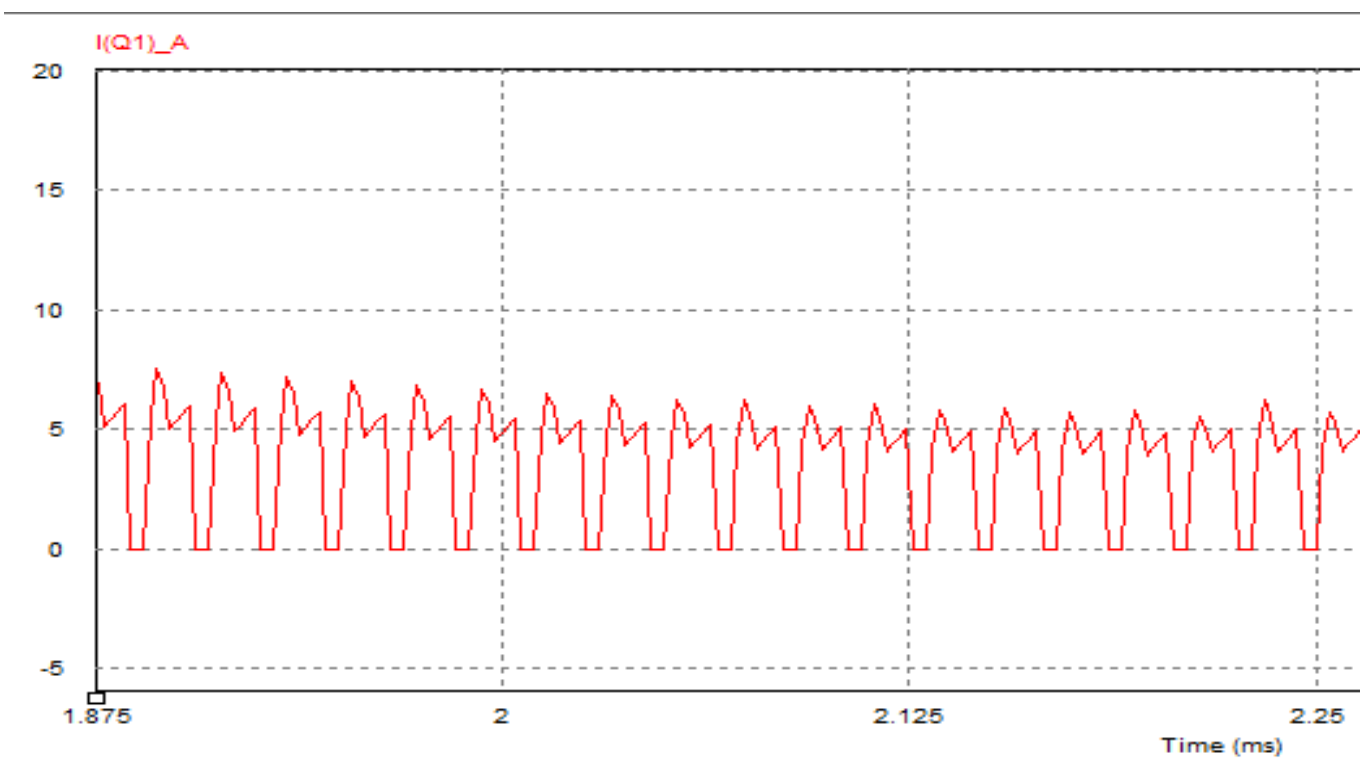

Figure 3 - Input current and switch.

Source: Authors

According to Figures 4 and 5, the voltage in the VS1 switch in the capacitors $\mathrm{C} 1$ and $\mathrm{C} 2$ in the diodes D1 and D2 is the same, being half of the output voltage as calculated in equation 6 . The diode Do has the same voltage of Co, which is the output voltage as shown in equation 7 .

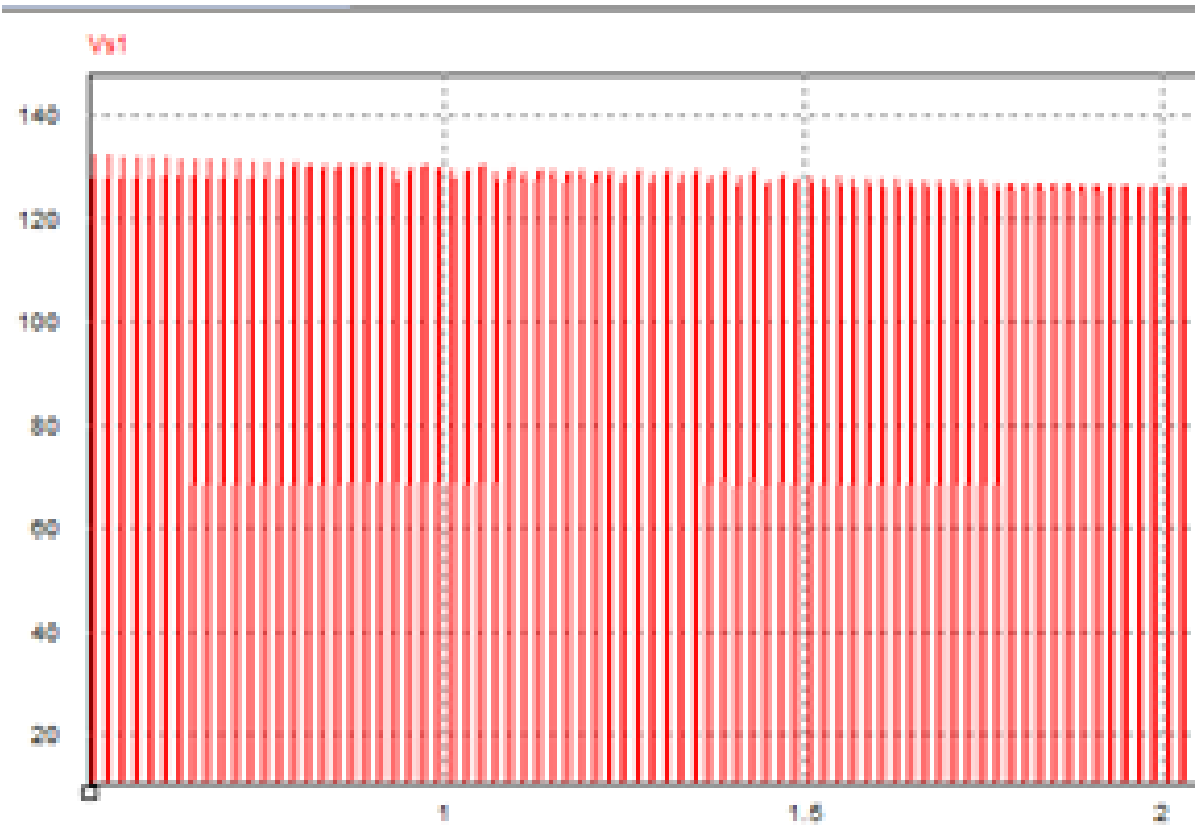

Figure 4 - Voltage on S-switch, Capacitors C1 and C2, D1, D2 and D0.

Source: Authors 
The great advantage of the non-isolated CC boost converter with Multiplier Voltage is that it lowers the stress on the switch and other components because voltage in these components is half the output voltage.

According to Figure 5, the average current in the diodes should be equal to the output current of the Io converter, an average value of currents in these components of $0.5 \mathrm{~A}$ and an RMS value of $2.4 \mathrm{~A}$ were obtained in the simulations.

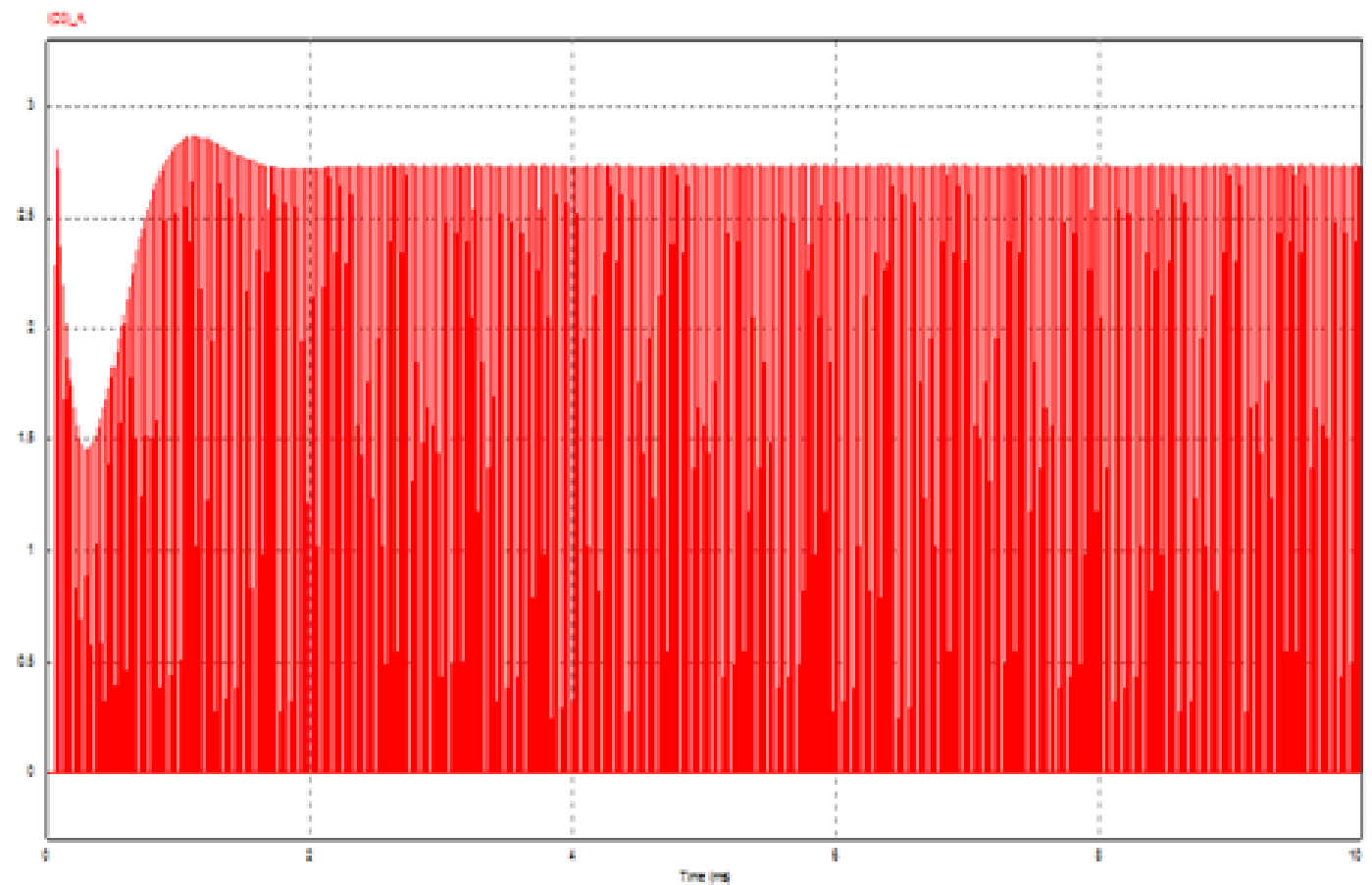

Figure 5 - Average current in the Diodes Source: Authors

Figure 6 shows the output current calculated in equation 11.

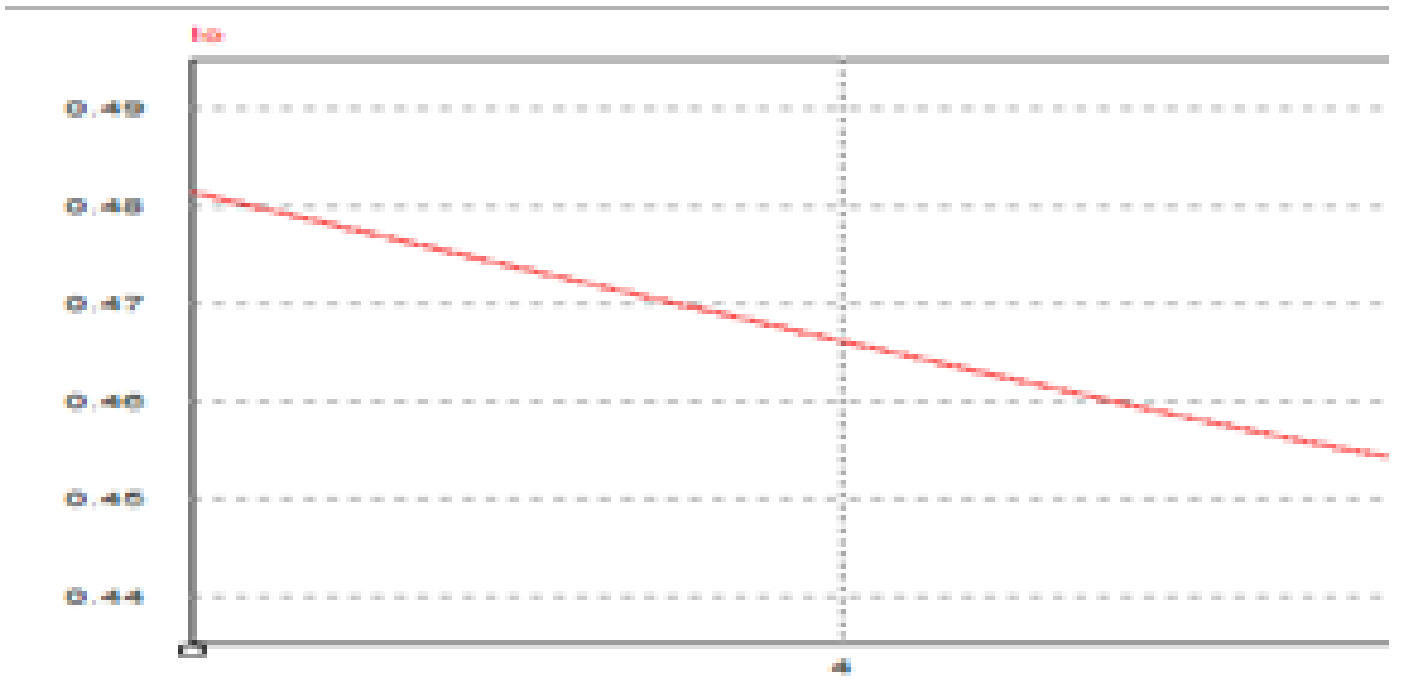

Figure 6 - Output current

Source: Authors 
The output voltage in the converter had a gain of 8.3 according to equations 1 and 7 as shown in figure 7 .

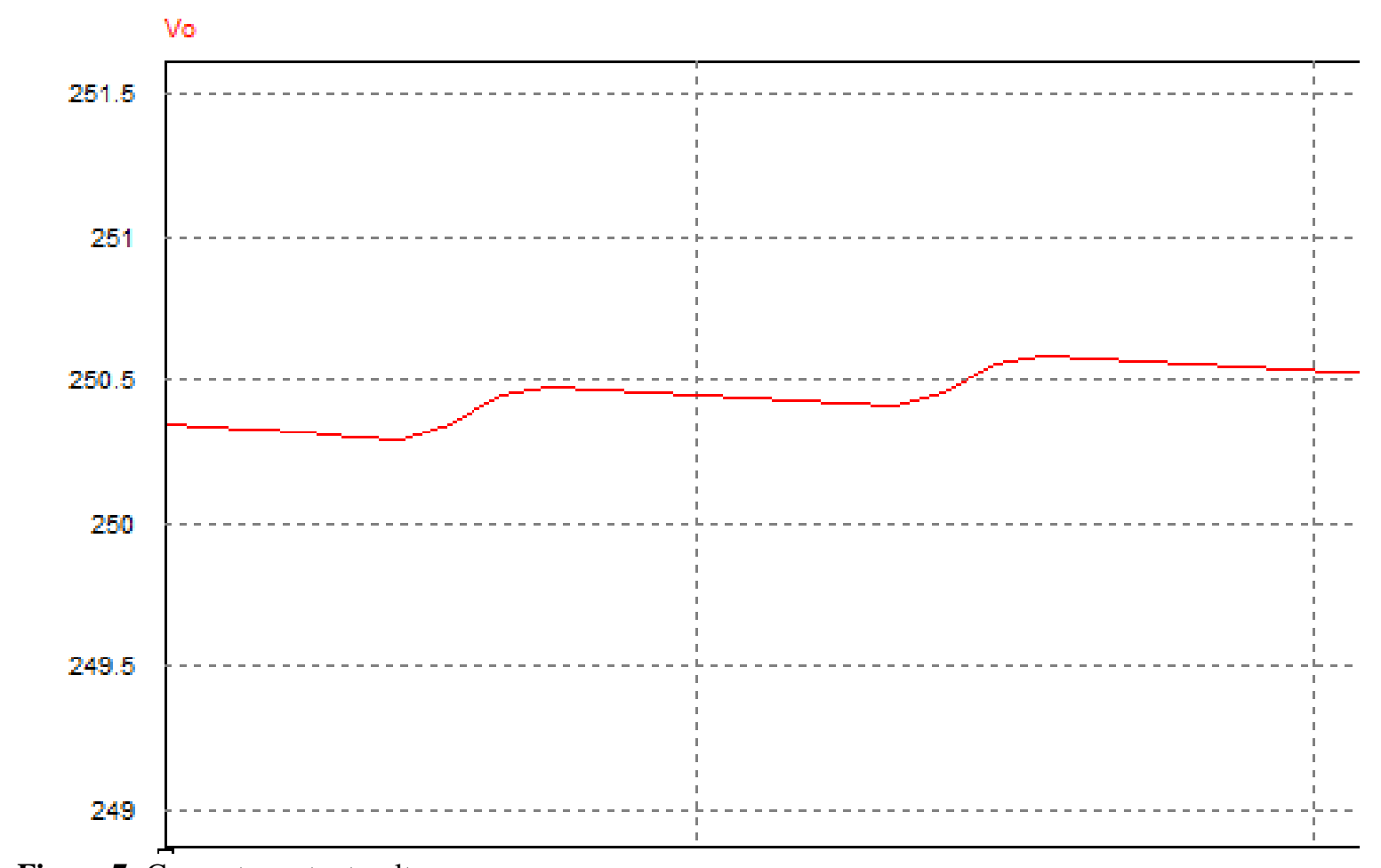

Figure 7- Converter output voltage.

Source: Authors

Table 3 shows the values calculated and simulated with the experimental data.

Table 3 - Project Specifications

\begin{tabular}{ll}
\hline $\begin{array}{l}\text { Calculated and simulated } \\
\text { values }\end{array}$ & $\begin{array}{l}\text { Experimental values with rotation } \\
\text { of 250 revolutions per minute. }\end{array}$ \\
\hline $\begin{array}{l}\text { Output voltage }=250 . \text { Current } \\
\text { In=Is } 1=5,3 \mathrm{~A}\end{array}$ & $\begin{array}{l}\text { Output voltage }=62 \mathrm{~V} \\
\text { Current 2,1 } \mathrm{A}\end{array}$ \\
\hline
\end{tabular}

The current and power values of the experimental data were smaller in comparison to the simulated data because the rotation was smaller in relation to the nominal rotation of the generator, resulting in a decrease in the input voltage.

The main advantage of the converter studied is the high static gain without the use of transformers. Another result observed was the low switching loss and less effort in the Mosfet switch, due to voltage reduction and low current. The boost converter with multiplier cell shown above is responsible for regulating the CC bar voltage of the system.

A voltage inverter is being developed in the prototype, which are suitable structures for converting $\mathrm{CC}$ to $\mathrm{AC}$ voltage, thus being able to control the level of the output voltage value and the fundamental and elementary frequency. thus connecting the system to electric power grid.

Considering the different characteristics of physical conditioning among cyclists to define the minimum and maximum levels of energy production, 
simulations with different levels of voltage and current for the generation, which will allow the tracking of the maximum power point, increasing the efficiency of the system will be carried out.

\section{CONCLUSION}

In this work, a system for generation and control of electric energy obtained through effort of cyclists in a pedal coupled to a generator was presented. The preliminary results showed that the proposed method and prototype are promising because they are able to deal with the different problems of energy oscillation inherent in the system, besides the possibility of allowing the installation of other microgeneration sources with the same characteristics of inconstancy.

Future improvements are being studied and carried out as a methodology that is under development to solve the problem of interconnection to the conventional electric grid, that is, to provide the use of this energy generated for use in the other and different loads of the conventional electric system CA.

\section{REFERENCES}

1- Chalermthai, Barhra. Sada, Nisrein. Sarfraz, Omer. Radi, Bahaa. Recovery of Useful Energy from Lost Human Power in Gymnasium. *Department of Electrical Engineering and Computer Science, Masdar Institute of Science and Technology Abu Dhabi, United Arab Emirates, 2015.

2- Dias, Leandro Rosa. Lima, Gustavo Brito. Rodrigues, Danillo Borges. Sistema de Geração de Energia Elétrica a partir de uma Bicicleta Ergométrica. Escola de Engenharia de São Carlos (EESC) - Universidade de São Paulo (USP), São Carlos - SP. Instituto de Ciências Tecnológicas e Exatas (ICTE), Universidade Federal do Triângulo Mineiro (UFTM), Uberaba - MG, Outubro de 2016.

3- Falcão, D.M. Integração de Tecnologias para Viabilização da Smart Grid. Rio de Janeiro RJ, Agosto de 2011.

4- $\quad$ Fachin, Odilia. Fundamentos de metodologia. 6aed São Paulo: Saraiva, 2005

5- Gilmore, Adam M. Human Power: Energy Recovery from Recreational Activity. Guelph Engineering Journal, (1), 8 - 16. ISSN: 1916-1107. (C2008.

6- Lakatos, Eva Maria. Marconi, Marina de Andrade. Fundamentos de metodologia científica. 5. ed. São Paulo: Atlas 2003.

7- Prudente, Marcos. Pfitscher, Luciano L. Emmendoerfer, Gustavo. Romaneli, Eduardo. Gules, Roger. Voltage Multiplier Cells Applied toNon-Isolated CC-CC Converters. Ieee Transactions On Power Electronics, Vol. 23, No. 2, March 2008. 